Federal Reserve Bank of Minneapolis Research Department

\title{
The Role of Damage-Contingent Contracts in Allocating the Risks of Natural Catastrophes
}

\author{
R. Anton Braun, Richard M. Todd, and Neil Wallace*
}

Working Paper 586D

April 1998

\begin{abstract}
The distinguishing feature of natural-catastrophe risk is claimed to be aggregate risk. Because such risk is encompassed in the general competitive model, it seems to pose no new theoretical challenge. However, that model has markets contingent on exogenous events, while the actual economy seems to be developing mainly markets contingent on the level of total damage. In the context of a model with aggregate risk and endogenous total damage, a notion of competitive markets contingent on total damage is formulated. That notion implies that such markets achieve the same (efficient) risk sharing as markets contingent on exogenous events.

*Braun, International University of Japan; Todd, The Federal Reserve Bank of Minneapolis; Wallace, The Pennsylvania State University and The Federal Reserve Bank of Minneapolis. The authors acknowledge the help of Brian Atwater, Karen Hovermale, Jean Rawson, and Ron Feldman. Much of the work for this paper was done while Braun and Wallace were in residence at the Research Department of The Federal Reserve Bank of Minneapolis. We are indebted to the Bank for research support. However, the views expressed are those of the authors and not necessarily those of the Bank or the Federal Reserve System. For communications to the authors, contact Neil Wallace, The Pennsylvania State University, Department of Economics, 608 Kern Graduate Building, University Park, PA 16802 or via e-mail to <neilw@psu.edu>.
\end{abstract}




\section{Introduction}

As measured by the damage inflicted on property, the past decade has been marked by unusually severe natural catastrophes. Insured damage from Hurricane Hugo in 1989, over $\$ 5$ billion in 1997 dollars, exceeded by more than $50 \%$ the largest insured loss from previous natural catastrophes. Three years later, insured losses from Hurricane Andrew reached almost four times those caused by Hugo, and the Northridge earthquake of 1994 caused insured damage at nearly double Hugo's level. Elsewhere, Europe has recently experienced unprecedented losses from wind storms, and Japan experienced property losses in the Kobe earthquake of 1995 that exceeded all previous postwar catastrophe losses.

These recent natural catastrophes and fears of even larger catastrophe losses have raised concerns that existing arrangements for sharing the risks of natural catastrophes are inadequate. ${ }^{1}$ In response to such concerns, governments have taken up or enacted initiatives involving government-sponsored insurance or reinsurance programs. Insurance commissioners in Florida, Hawaii, and California all expanded their state's residential property insurance programs. Lawmakers in all three states subsequently enacted new state-run property insurance programs aimed at assuring the availability of catastrophe coverage, and Florida's new program quickly became the second largest provider of homeowners insurance in the state. At the federal level, an insurance industry proposal for a government-backed reinsurance fund was introduced into the Senate, and the Clinton administration and some Republican senators countered with a proposal that the federal government auction off reinsurance coverage for losses in the $\$ 25$ to $\$ 50$ billion range. Any such program would be in addition to existing federal crop and flood insurance programs and federal catastrophe relief programs.

These events and the responses to them lead us to ask what is special about risks related to natural catastrophes. Asymmetric information- which potentially gives rise to moral hazard, adverse selction, and costly ex post verification-seems, if anything, less severe in the context of natural disasters than it does in some other types of risky situations. While insurance could

\footnotetext{
${ }^{1}$ Insurance industry sources claim that the US industry cannot cope with catastrophe losses that exceed $\$ 40$ billion ([10, pp.21,26];[9]). Others have also questioned the adequacy of current arrangements for re-insurance, whereby insurance companies transfer some of their own risks and a share in the associated premium income to other companies $([5] ;[12] ;[32] ;[33] ;[11])$.
} 
induce property owners to take fewer precautions than they otherwise would, such possibilities seem to be dealt with well using deductibles. Adverse selection seems not to be a severe problem because potential insurers seem at least as knowledgable about exposure to natural disaster risks as are individual property owners. Nor does costly ex-post verification pose special problems, although major disasters do seem to strain the insurance-adjuster resources of the insurance industry. We are, therefore, led to conclude that the special feature of natural catastrophes is that they pose risk in the aggregate. ${ }^{2}$

By risk in the aggregate we mean risk that does not average out among people. For risk that does average out among people, the ideal outcomeabstracting, as we will do throughout, from asymmetric information- is an arrangement whereby each individual's well-being is unaffected by what actually happens. Each person buys insurance and is made whole if the person happens to suffer a loss. In the presence of aggregate risk, such immunity from actual events is, by definition, impossible. In other words, with aggregate risk, at least some people's well-being must be contingent on actual events.

Such contingent well-being does not, by itself, pose a new challenge to ordinary economic theory. The basic economics of sharing risk, including aggregate risk, is clear and well accepted; it is included in the standard economic framework known as the Arrow-Debreu general equilibrium model. Moreover, that theory encompasses many realistic features including the possibility that individuals disagree about the probabilities of various natural catastrophes. What may seem unrealistic about the theory is that it posits complete markets contingent on exogenous events. In the actual economy, we generally see, at best, markets contingent on the amount of insured damage. ${ }^{3}$ Our purpose in this paper is to show that such contingencies can be equivalent to contingencies based on exogenous events. Such equivalence is important because a standard result is that complete markets contingent on exogenous events achieve efficient (Pareto efficient) risk-sharing.

We begin, in section 2, by reviewing evidence that suggests that natural catastrophes pose aggregate risk. We then develop a series of simple models in which we highlight the essential differences between optimal risk sharing arrangements in the presence and absence of aggregate risk and in

\footnotetext{
${ }^{2}$ In [15], a similar conclusion is reached for crop insurance.

${ }^{3}$ There are exceptions. Recently a bond contingent on the Richter scale intensity of earthquakes in the Tokyo region was marketed (see [8] and [20]) and in the 1980s Chubb Insurance briefly offered a contract contingent on Midwestern rainfall.
} 
which we demonstrate the equivalence between complete markets contingent on exogenous events and markets contingent on insured damage. In section 3 , we present four versions of endowment economies. These models are presented mainly for expository purposes and serve to highlight the difference between aggregate and no-aggregate risk situations. In them, the equivalence between markets contingent on exogenous events and those contingent on insured damage follows because total damage is exogenous. In section 4, we present a model with aggregate risk, groups that are diverse in terms of their exposure to risk, and, most important, choices about whether to invest resources where they are subject to aggregate risk. The last feature makes total insured damage endogenous. In the context of that model, we show the equivalence between complete markets contingent on exogenous events and markets contingent on insured damage.

\section{Natural Catastrophe Damage}

In most locations in a given year, natural catastrophes are unlikely, just as accidents are unlikely for most automobiles in a given year. Nonetheless, it is guaranteed that every year some locations will be hit by natural catastrophes, just as it is given that every year some automobiles will crash. For the insurance industry a critical question is whether the per person damage, say in a year, can be predicted. For automobile accidents, the large number of drivers, the relatively small effect of any one accident, and the lack of connection between one accident and others allow application of the law of large numbers, so that average annual losses can be predicted fairly well. We argue that that is not true for all natural catastrophes.

Average losses from some types of natural catastrophes may be predictable. Tornadoes accounted for about 30 percent of the claims paid by the US insurance industry for property damage due to natural catastrophes over the period 1984-93 ([10]). Despite being costly overall, tornadoes are numerous and each tornadic storm affects only a small area, so that the average damage is fairly predictable. Earthquake and hurricane damage are very different. Both of these types of natural catastrophes are also fairly numerous, but most of them are not powerful enough, or not close enough to built-up areas, to cause much damage. Most of the damage from these threats occurs in the infrequent case of a powerful event hitting an urban area, such as when the Northridge earthquake shook the northern Los Angeles metro area 
or when Hurricane Andrew passed through the southern rim of the Miami area. The concentration of earthquake and hurricane losses in a relatively few powerful urban events gives rise to considerable year-to-year volatility in the amount of damage from these two types of catastrophe, and even to average losses from all catastrophes. Hurricane Andrew in 1992, the Northridge earthquake in 1994, and the Kobe earthquake in 1995 did more damage in those years than all other natural catastrophes combined. Estimates of their economic impact, including lost output due to business interruption, range from about $\$ 25$ billion for Andrew and Northridge ([22]) to about $\$ 200$ billion for Kobe ([23]). The fact that each of them was unpredictable and dwarfed all other natural catastrophe losses that year establishes that such catastrophes pose aggregate risk.

But how significant is this aggregate risk? The models we present are of interest if aggregate risks are large relative to output. But how large, and compared to what measure of output? One benchmark is set by business cycle recessions, which the financial industry views as posing significant undiversifiable risk. In typical US recessions, output dips below trend by 2 to 3 percent for a year or two. On this basis, aggregate catastrophe risks equal to or greater than 2 percent of annual output can safely be considered large, and even lower thresholds may be relevant. As to the relevant measure of output, this will depend on how integrated the world insurance market is. A conservative approach would be to assume full integration and compare catastrophe losses to world output. Narrower measures are relevant to the extent that international insurance markets are not integrated, perhaps as a result of restrictions on international trade. We will consider losses relative to both national output and total output of the industrial countries, which we call world output. Applying the 2 percent standard to world output of about $\$ 30$ trillion implies a dollar threshold of about $\$ 600$ billion for large aggregate risks due to annual variability in natural catastrophe losses.

The US insurance industry seems to have a different standard in mind, however. Apparently reflecting the actual amounts of reinsurance, policyholder surplus, and loss reserves, the industry claims that $\$ 40$ billion is near the maximum amount of coverage it can provide for catastrophe losses ([10]). Since not all losses are insured, the industry is saying that it can cover insured losses for natural catastrophes whose total losses run about $\$ 60$ to $\$ 80$ billion. We will accept $\$ 80$ billion in losses as a reasonable standard for a catastrophe to pose aggregate risk, even though it represents only about a third of a percent of world output. One reason is that losses of this magnitude 
have been accepted in the policy debates of natural catastrophe insurance as defining an event too large for the private sector, and maybe even the government, to insure.

Of course, if we consider all possible catastrophes without regard to probability, then truly enormous catastrophes become relevant. For example, scientists believe that a large meteoroid striking about 65 million years ago near what is now the Yucatan peninsula caused worldwide devastation, including blast, fire, ash deposit, and prolonged obliteration of the sun. Losses from a repeat of this event, which is thought by some to have contributed to the extinction of dinosaurs, would be truly astronomical. Devastating meteoroid collisions are not very frequent, however. When probability of occurrence is considered, earthquakes and hurricanes emerge as the most likely threats, with some risk also from floods, tornadoes, and other storms. In at least one case, these risks do seem significant.

The extreme case we have in mind is a major earthquake in the Tokyo Bay region. The Pacific and Philippine Oceanic plates converge at an angle near Tokyo, creating the Sagami Trough, where crustal material from one plate is force below the other. Relative movements of the plates cause stress to accumulate, and sudden releases of this stress cause periodic earthquakes. One such release along the Sagami Trough is thought to have caused the great Kanto earthquake of 1923, which claimed about 143,000 lives and caused about $\$ 68$ billion in property damage ([23, p.17]). Recent estimates of the effects of a repeat of this historical event suggest that far fewer lives would be lost but that property damage would be much higher, about $\$ 1$ trillion ([23, Table 1-1 and p. 8]). Another $\$ 1$ trillion of output could be lost due to business interruption, the temporary inability of businesses to produce goods and services in the weeks and months after the catastrophe ([23, Table 1-1]). The combined $\$ 2$ trillion dollar impact amounts to almost 7 percent of annual world output, a large figure by almost any standard.

Studies from the 1980s ([18];[36]) suggest that the risk of another severe rupture of the Sagami Trough near Tokyo is not particularly high now. The quake in 1923 occurred 220 years after the previous severe rupture in that area, and the 1980s studies estimated an average recurrence interval of about that length for such events. In the 1990s, however, faith in precision of earthquake probabilities seems to have weakened. Geologists have come to view fault systems as more interactive with one another and hence more dynamically complex than allowed for in earlier studies of recurrence intervals ([31, pp.63,64]) The unexpected Kobe quake underscored the complexity of quake 
forecasting. Given Tokyo's history of severe earthquakes, its extraordinary concentration of loss exposures, and the high risks either on nearby fault lines or on the Sagami Trough itself at some point in the future, the natural catastrophe risks in the Tokyo area appear to be globally significant.

The Kobe quake of 1995 is estimated to have caused total damage, including business interruption, in the neighborhood of $\$ 200$ billion. The largest known earthquake risks in the US seem to involve losses on a par with those in Kobe. According to some recent estimates, both the San Francisco Bay Area and the Los Angeles basin can expect about $\$ 175$ billion in property damage and business interruption under realistic near-worst-case scenarios, with about a 10 percent probability that the losses would exceed $\$ 220$ billion in such an event ([21, p.3]; [22, p.3]). Moreover, the natural events that would give rise to such losses are thought to have a nontrivial probability of ocurring ([21, p.12] and [22, p.13]). These California earthquake risks, as well as the actual losses experienced in Kobe, Japan, amount to about $0.6 \%$ of annual world output, less than a serious worldwide recession but far in excess of our $\$ 80$ billion threshold.

Earthquake risks outside of San Francisco or Los Angeles are either smaller or less well known than the California risks, and the likely damage from a single hurricane is probably smaller than from the California quakes. However, the odds of one of these other events exceeding $\$ 80$ billion also appear nontrivial.

Hurricane Andrew highlighted the destructive potential of intense hurricanes in urban areas. Estimates of the damage that Andrew would have caused had it traveled just 20 miles north of its actual path through Florida exceed $\$ 100$ billion ([3]). An insurance industry executive estimates that a hurricane that hit Florida and continued up the East Coast might cause $\$ 100$ billion in insured losses, which would translate into $\$ 150$ to $\$ 200$ billion in total losses, or nearly as much as a great California earthquake ([9]). New Orleans is potentially at even greater risk than East Coast cities, because much of its land mass is below sea level, protected by levees whose ability to withstand the storm surge of a category 4 or 5 hurricane is untested. Some studies ([7]) suggest that east coast hurricane activity is in the early stages of a two or three decade upswing, and others estimate that a recurrence of the hurricane patterns of the 1940's and 1950s would in some years give rise to losses of $\$ 100$ billion or more in either New England or Florida and possibly both ([3]). With over 60 million Americans living in hurricane-prone areas and insuring over $\$ 2$ trillion in property, the potential for hurricane damage 
is high.

Except for earthquake risks in Japan, which are large by any reasonable measure, most large natural catastrophe risks are currently estimated to fall in the range of $\$ 100$ to $\$ 200$ billion dollars for a single event. The recent spate of catastrophes, from Hurricane Andrew through the Northridge and Kobe earthquakes, shows that multiple occurrence of large-scale catastrophes is also possible, raising the overall level of aggregate risk.

\section{Models with Exogenous Damage}

We here present four endowment (pure exchange) models which share some general features. Each is a static model populated by risk-averse people who maximize expected utility. In the models, we distinguish between individual and aggregate risk. The aggregate risk can be thought of as being the severity of a natural catastrophe. The individual risk is about who actually suffers the damage from a natural catastrophe of a given severity. We will always suppose that for a given severity, the damage falls in a random way among the members of some group. As this suggests, all of our models will have groups that are ex ante identical: groups that face the same kind of risk. In describing Pareto efficient (PE) allocations, we will generally limit ourselves to those that treat equally all those who are ex ante identical. Such allocations are called equal-treatment Pareto-efficient (ETPE) allocations. One reason for focusing on equal treatment (ET) allocations is that "market" determined allocations are always ET allocations. Throughout we assume symmetric information.

For each model, we describe the ETPE allocations and also describe the allocations produced by some "market" arrangements. All the models are special cases of standard models. For such models, it is known that a competitive equilibrium gives rise to an allocation that is PE. In the context of models with risk, this result obtains if there are markets contingent on the underlying risk outcomes. In these endowment economies, securities contingent on total damage are trivially equivalent to securities contingent on the underlying risk outcomes because total damage is exogenous. 


\subsection{Identical people and no aggregate risk}

There are $N$ people, $M$ of whom, where $0<M<N$, will realize an ex post endowment $w_{1}$, while the remaining $N-M$ will realize $w_{2}$, with $w_{1}<w_{2}$. We interpret those who get the lower endowment as experiencing a loss. Ex ante, each person has probability $M / N$ of experiencing that loss. In other words, a natural catastrophe will do a known amount of total damage and the damage will be distributed in a random way among ex ante identical people.

Since there is only one ex ante group here, there is only one ETPE allocation. And since we are assuming that each person does not like risk, this allocation has each person consuming the same amount ex post regardless of whether or not the person experiences a loss. The amount consumed, denoted $c$, is $\left[M w_{1}+(N-M) w_{2}\right] / N$. This amount is simply the per capita amount of the good available, which is always the same in this model. Notice that this allocation has complete insurance in the sense that the ex post situation of a person does not depend on the whether the person ends up experiencing a loss or not.

This is a model of a situation with individual risk, but no risk in the aggregate. Moreover, we can describe how the unique ETPE is achieved through an insurance contract- one, however, that differs from ordinary insurance in a small detail: instead of premiums being paid up front, they are paid after the outcome is realized. We can have each person pay a premium equal to $w_{2}-c$ and have those who suffer a loss receive $w_{2}-w_{1}$, so that each person ends up with $c$. With $c$ chosen as above, it follows that total premiums, $N\left(w_{2}-c\right)$, equal total payments, $M\left(w_{2}-w_{1}\right)$. It also follows that the insurance is actuarily fair in the sense that the premium, $\left(w_{2}-c\right)$, is equal to the expected payment, $(M / N)\left(w_{2}-w_{1}\right)$.

\subsection{Different groups ex ante and no aggregate risk}

For our purposes, it suffices to suppose that there are 2 groups of people. There are $N_{1}$ people in group 1 . These are exactly like those described in the previous model: $M$ of these people will experience a loss, where $0<M<N_{1}$; that is, $M$ people will get an ex post endowment $w_{1}$ and the remaining $N_{1}-M$ will get $w_{2}$ with $w_{1}<w_{2}$. The ex ante probability that each of the people in group 1 experiences a loss is $M / N_{1}$. There are $N_{2}$ people in group 2 and we will make them different from group 1 in that each will realize an endowment 
$w_{3}$. This model can be interpreted as one in which the world consists of two regions. Region 1 is populated by $N_{1}$ people who are identical ex ante. A natural catastrophe will occur and do a known amount of total damage in region 1, $M\left(w_{2}-w_{1}\right)$, with the damage distributed in a random way among all the people in region 1 . There is a second region, region 2, which is populated by $N_{2}$ people, who are not subject to any natural catastrophe.

Since there are now two groups, there are many ETPE allocations. However, since people are risk-averse, each has the property that no person's ex post situation will depend on which of the $N_{1}$ people experience a loss. Hence, the set of ETPE allocations consists of all nonnegative pairs $\left(c_{1}, c_{2}\right)$ that satisfy $N_{1} c_{1}+N_{2} c_{2}=\left[M w_{1}+\left(N_{1}-M\right) w_{2}\right]+N_{2} w_{3}$, where $c_{1}$ is the ex post consumption of each person in group 1 and $c_{2}$ is that of each person in group 2. Notice again that any ETPE allocation has complete insurance in the sense that the realized situation of people who are ex ante identical does not depend on whether or not they happen to be among those who experience the lower endowment.

One of these ETPE allocations is special in that it is the competitive equilibrium outcome; it is $c_{1}=\left[M w_{1}+\left(N_{1}-M\right) w_{2}\right] / N_{1}$ and $c_{2}=w_{3}$. That is, there is no basis for trade between the two groups in this model. As above, this outcome can be achieved by all the members of group 1 participating in actuarily fair insurance among themselves.

Other ETPE allocations can be achieved through policies that tax one group and subsidize the other. One such policy resembles government catastrophe relief. Suppose that the policy consists of levying an ex post tax of $d$ on every person, independent of group, and dividing the proceeds among those who experience a loss. Also, suppose that the policy is in place before anyone enters into any voluntary insurance arrangment so that the voluntary insurance that people in group 1 buy can be affected by the magnitude of $d$. It is obvious that the resulting amended competitive equilibrium allocation is an ETPE allocation with $c_{1}=\left[M w_{1}+\left(N_{1}-M\right) w_{2}\right] / N_{1}+N_{2} d / N_{1}$ and $c_{2}=w_{3}-d$. The catastrophe relief in this model is a pure income transfer and, therefore, seems completely arbitrary. In particular, there is nothing in the model that says that the people in group 1 would be worse off than the people in group 2 without the catastrophe relief policy. Also, the amount of "private" insurance purchased falls in the presence of catastrophe relief; the premium falls by $N_{2} d / N_{1}$ and the payoff falls by $N_{2} d / M$. 


\subsection{Identical people and aggregate risk}

Suppose now that there are $N$ people, as in the first model, but that the number of them who will suffer a loss is itself random. We suppose that there are $K$ possible outcomes, numbered $1,2, \ldots, K$. Associated with each outcome is a number of people who will experience a loss of $w_{2}-w_{1}$; we let $M_{k}$ denote the number who experience a loss in outcome $k$, where $M_{k+1}>M_{k}$ and $M_{1} \geq 0$ and $M_{K}<N$. In outcome $k$, the probability that any one person will experience a loss is $M_{k} / N$. We call each of the possible $K$ outcomes an aggregate state. ${ }^{4}$ As in the first model, the world here is populated by identical people ex ante. A natural catastrophe will do one among the following levels of total damage, $M_{1}\left(w_{2}-w_{1}\right), M_{2}\left(w_{2}-w_{1}\right), \ldots, M_{K}\left(w_{2}-w_{1}\right)$, and the $k t h$ level of total damage is distributed among $M_{k}$ randomly selected individuals. In order to maintain the assumption that people are ex ante identical in this world, we, for now, assume that they agree about the probabilities with which each aggregate state occurs. In keeping with that assumption, we let $p_{k}$ be the probability that $M=M_{k}$.

In such a world, there is only one ETPE allocation. The allocation has the property that the ex post situation of a person does not depend on whether or not the person experiences a loss. Given that feature, the allocation is determined by total resources as follows: in aggregate state $k$, the ex post consumption of each person, denoted $c_{k}$, is $\left[M_{k} w_{1}+\left(N_{1}-M_{k}\right) w_{2}\right] / N$. Since $c_{k}$ is a weighted average of $w_{1}$ and $w_{2}$ with a weight on the smaller endowment $w_{1}$ that is larger the larger is $M_{k}$, it follows that $c_{k}$ is lower the larger is $M_{k}$. Notice that the ETPE allocation has complete insurance in the sense that the ex post situation of a person does not depend on whether or not the person experiences the lower endowment $w_{1}$. However, the ex post situation of everyone depends on the aggregate state.

As was true for the first model, we can describe how the unique ETPE is achieved through an insurance contract- one that again differs from ordinary insurance in having premiums paid after the outcome is realized. Now, however, the premium depends on the severity of the natural catastrophe; if $M=M_{k}$, then each person pays a premium equal to $\left(w_{2}-c_{k}\right)$ and each person who suffers a loss receives $w_{2}-w_{1}$, so that each person ends up with $c_{k}$. With $c_{k}$ chosen as above, it follows that total premiums, $N\left(w_{2}-c_{k}\right)$, equal total payments, $M_{k}\left(w_{2}-w_{1}\right)$. Notice that these premiums look like those

\footnotetext{
${ }^{4}$ This specification of aggregate and individual risk and the results in this section are identical to those in [2]. The model and results in the next section are quite different.
} 
from a mutual insurance company- where the premium plus any dividend or extra assessment depends on how much the company must pay out. ${ }^{5}$

\subsection{Different groups ex ante and aggregate risk}

This model combines the features of the previous two models. There are $N_{1}$ people in group 1. These are exactly like those described in the last model. There are $N_{2}$ people in group 2 and each of them will realize an endowment $w_{3}$. We begin by assuming that everyone agrees about the probabilities of the different aggregate states so that $p_{k}$ is the probability that total damage is $M_{k}\left(w_{2}-w_{1}\right)$, where $0 \leq M_{1}<M_{2}<\ldots<M_{K}<N_{1}$. Like the second model, this model can be thought of as a world with two regions. Region 1 is subject to catastrophes which do a random amount of total damage that is distributed in a random way among the $N_{1}$ people in region 1 . Region 2 is not subject to catastrophes.

As in the second model, there are now many ETPE allocations. However, each has certain properties. First, for any given aggregate state, any ETPE allocation is such that the ex post situation of a person does not depend on whether the person is among those who experience damage. In this sense, any ETPE allocation has complete insurance. Given this property, we can describe ETPE allocations by describing the ex post situation of members of each group contingent on the aggregate state; say, by $c_{1}=\left(c_{11}, c_{12}, \ldots, c_{1 K}\right)$ and $c_{2}=\left(c_{21}, c_{22}, \ldots, c_{2 K}\right)$, where $c_{i k}$ is the ex post consumption of a member of group i in aggregate state $k$. A second property of any ETPE allocation is that the risk implied by the aggregate state be distributed appropriately among people in the two groups. There is, however, no mechanical way to describe the $c_{1}$ and $c_{2}$ vectors that satisfy this condition, and, hence, are ETPE allocations. We can, however, explain why any ETPE allocation has the property that members of both groups bear some of the aggregate risk, by which we mean that $c_{1 k}>c_{1, k+1}$ and $c_{2 k}>c_{2, k+1}$.

Consider a feasible ET allocation that satisfies the first property of ETPE allocations, complete insurance, but has none of the aggregate risk being borne by members of one group. Then, as we now explain, there is a feasible alternative ET allocation that makes everyone better off. In such an initial allocation, each member of one group has the same ex post consumption independent of the magnitude of the catastrophe. A well known result in the

\footnotetext{
${ }^{5}$ For an earlier discussion of insurance using the mutual principle, see [13].
} 
economics of risk is that starting from such a certainty situation, any person is made better off by betting a small amount at any odds that are favorable. As applied to the current situation, this result says that each member of the group bearing none of the aggregate risk can be made better off by taking on a small amount of the aggregate risk at any favorable odds. It is also the case that members of the group that bear all the aggregate risk can be made better off by shedding some of it at odds that are somewhat unfavorable. It follows that any ETPE allocation has the property that members of each group bear some of the aggregate risk.

Now we describe market arrangments for achieving ETPE allocations. We first describe a competitive equilibrium $(\mathrm{CE})$. In the context of the current model, one set of trades that achieves a CE allocation, and, hence an ETPE allocation, is as follows. One part of the trades involves exactly the insurance described in the last model. Let $y_{1 k}$ denote the resulting ex post "income" of each member of group 1 in aggregate state $k$, where $y_{1 k}=\left[M_{k} w_{1}+\left(N_{1}-\right.\right.$ $\left.\left.M_{k}\right) w_{2}\right] / N_{1}$. If there are futures markets in which people can go long or short on the occurrence of each level of total damage- in effect, place bets on the occurrence of each aggregate state- then there is trade in such markets. With unanimity about the probabilities of the different aggregate states, the members of group 1 will bet for the worse aggregate states and against the best aggregate states and vice versa for the members of group 2 .

We now describe these trades in more detail. Consider a market in output in aggregate state $k$ with a price $s_{k}$ defined in the following way. Buying $x$ in this market means agreeing to give up $s_{k} x$ if the aggregate state is not $k$ in exchange for collecting $x$ if the state is $k$, while selling $x$ on this market means agreeing to give up $x$ if the aggregate state is $k$ in exchange for collecting $s_{k} x$ if the state is not $k$. Since the aggregate state $k$ can also be described unambiguously as an amount of total damage, $M_{k}\left(w_{2}-w_{1}\right)$, it is equivalent to make the contingency in this market total damage. The prices $s_{1}, s_{2}, \ldots, s_{K}$ are determined by supply and demand. In particular, in an equilibrium, the total amount bought equals the total amount sold for each state $\mathrm{k}$.

If we maintain all the assumptions made above, including the assumption that there is unanimity about the probabilities of the different aggregate states, then we can say something about the direction of trade on some of these markets and something about the prices. In the futures market for the worst aggregate state, members of group 1 are buyers and members of group 2 are sellers and the price $s_{K}$ exceeds $p K /(1-p K)$, the actuarially fair price. The reason is that members of group 2 have to be induced by better than 
fair odds to take on some of the risk of the worst state occurring. In the futures market for the best aggregate state, members of group 1 are sellers and members of group 2 are buyers and the price $s_{1}$ is less than $p_{1} /\left(1-p_{1}\right)$, the actuarially fair price- again because members of group 2 have to be induced to take on the some of the risk of something other than the best state occurring. In the special case when aggregate risk is small, the price $s_{k}$ is close to $p_{k} /\left(1-p_{k}\right)$, the actuarially fair price, and no one bears much risk.

It is important to note that the general theory does not require that there be unanimity about the probabilities of different aggregate states. This is important because in the context of natural catastrophes, there may not be widely agreed upon probabilities. Even in the absence of such unanimity, it remains true that any $\mathrm{PE}$ allocation has the property that conditional on the aggregate state, the ex post situation of a person does not depend on whether or not the person happens to experience a loss. It follows that a PE allocation can be achieved through the same two-stage market scheme described above. One stage involves exactly the insurance described above. Individuals in group 1 buy insurance which leads to the ex post "income" $y_{1 k}$ for each member of group 1 in aggregate state $k$. The second stage involves trade at the prices $s_{k}$ just defined. However, without unanimity about probabilities of the different aggregate states, we cannot describe the directions in which people trade.

The above schemes are market or laissez-faire schemes with no taxes and subsidies. There are other PE allocations (ETPE allocations in the case of unanimity about probabilities) that can be achieved through taxes and subsidies. One such scheme is again a catastrophe relief scheme. Now we can think of such a scheme as follows: the amount $d_{k}$ is collected from every person if aggregate state $k$ occurs and the proceeds are distributed equally to those who experience a loss. Such a scheme is no more justified in this model than in the second model; it produces an arbitrary income transfer from those in region 2 to those in region 1.

\section{A Model with Endogenous Damage}

In the models so far examined, the resources subject to risk from a natural catastrophe are exogenous; they are not the result of decisions made by people. That assumption gives rise to a trivial equivalence between contingencies based on total damage and on the underlying aggregate state. We 
now describe a model in which the amount of resources subject to risk is the result of individual decisions. For that we model we define two notions of competitive equilibrium: the standard notion and a notion that is applicable to a setting in which the contingencies are (endogenous) total damage. The definitions imply that the two notions are equivalent.

\subsection{Resources, technologies, and preferences}

There are $K$ aggregate states and there is one good per state. In state $k$, the probability that investment in the risky technology (investment in the area that is subject to a catastrophe) suffers a loss is denoted $m_{k}$ and $0 \leq m_{1}<m_{2}<\ldots<m_{K}<1$. We assume that $m_{k}$ is also the fraction of investment in the risky technology that experiences a loss in state $k$. People invest ex ante and consume ex post. There are $H$ types of people and a large number, $N$, of each type. A person of type $h$ has a given amount of ex ante resource, denoted $y_{h}$, which can be divided in any way between the following two constant-returns-to-scale linear technologies: a safe technology (investment in the region not subject to catastrophes) which per unit invested yields $w_{3}$ units of output and a risky technology which per unit invested yields $R_{h} w_{2}$ units of output with probability $1-m_{k}$ and $w_{1}$ with probability $m_{k}$ in state $k$. In keeping with the idea of loss, $R_{h} w_{2}>w_{1}$. Types of people differ regarding the attractiveness to them of investment in the risky technology. In particular, without loss of generality, we let $R_{h+1}>R_{h}$, so that higher indexed types have better risky technologies.

In order to have outcomes consistent with some resources invested in both technologies, we assume that the expected return of the best risky technology in the worst aggregate state, $\left(1-m_{K}\right) R_{H} w_{2}+m_{K} w_{2}$, exceeds the return from investment in the safe technology, $w_{3}$, and that the expected return of the worst risky technology in the best aggregate state, $\left(1-m_{1}\right) R_{1} w_{2}+m_{K} w_{2}$, is less than $w_{3}$.

As regards preferences, we continue to assume that each person cares about final consumption, is averse to risk, and maximizes expected utility, where utility for person $h$ is determined by the strictly increasing and strictly concave function, $u^{h}$. Here we will not assume that there is unanimity about the probabilities of the different aggregate states, even among those of the same type. Thus, we label a person by type and number, by the pair $(h, j)$, where $h$ is the type and $j$ is the number. We let $p_{h j}=\left(p_{h j k}, p_{h j k}, \ldots, p_{h j k}\right)$, where $p_{h j k}$ is the subjective probability for person $(h, j)$ that aggregate state 
$k$ occurs.

\subsection{The allocation of individual risk for a given aggre- gate state}

Any PE allocation in the above economy has the property that the realized situation of a person does not depend on whether the person happens to be among those who have realized a loss. Therefore, we can describe both PE allocations and allocations arising from market arrangements by dealing with risk in two stages, as we did earlier. We can suppose that there is a withintype insurance scheme that guarantees each type $h$ person in aggregate state $k$ a per unit return on type $h$ risky investment equal to the expected return on risky investment in that aggregate state; namely, $\left(1-m_{k}\right) R_{h} w_{2}+m_{k} w_{1} \equiv$ $w_{k h}$. This kind of sharing of individual risk can be achieved through mutual insurance; in particular, in aggregate state $k$ everyone of type $h$ pays an insurance premium equal to $R_{h} w_{2}-w_{k h}$ per unit that they had invested in the risky technology, while those suffering a loss receive $R_{h} w_{2}-w_{1}$ per unit of their investment that has suffered a loss. In what follows, we take as given the above perfect sharing of individual risk on risky investment in a given aggregate state.

\subsection{The allocation of investment and aggregate risk}

Given the complete sharing of individual risk described above, our model falls within the class of standard economic models for which it is known that a competitive equilibrium exists and that a competitive equilibrium allocation is PE. That competitive equilibrium formulation has markets contingent on the aggregate state. Our main task is to formulate a corresponding notion of competitive equilibrium with markets contingent on total damage.

For any given amount of investment made subject to risk, there will be $K$ different levels of total damage. Therefore, we can represent markets contingent on total damage by a $K$ component list where component $k$ is a pair $\left(L_{k}, d_{k}\right)$, and where $L_{k}$ is the total damage and $d_{k}$ is the price of one unit of ex post output contingent on the total damage being $L_{k}$. Because

of the way we have ordered aggregate states, it follows that $L_{k}<L_{k+1}$. To mimic the competitive notion, we suppose that each person treats the list of $\left(L_{k}, d_{k}\right)$ pairs parametrically. That is, not only does each person ignore 
the possible effects on prices of the person's purchases and sales, but each person also ignores the effect of the person's own investment decision on total damage. Although the latter seems like an extra assumption, it is implicit in the former.

We let $c_{h j}=\left(c_{h j 1}, c_{h j 2}, \ldots, c_{h j K}\right)$, where $c_{h j k}$ is person $(h, j)^{\prime} s$ consumption in aggregate state $k$. Because it is well known that we do not have to index the investment decision by more than the person's type, we let $y_{h r}$ stand for $(h, j)^{\prime} s$ investment in the risky technology. Then, an allocation is a pair $\left(c_{h j}, y_{h r}\right)$ for each $(h, j)$. We now define both notions of competitive allocations.

Definition 1 An allocation is an Arrow-Debreu competitive allocation if it is feasible and if there exists $s=\left(s_{1}, s_{2}, \ldots, s_{K}\right)$ such that $y_{h r}$ maximizes $\left(y_{h}-y_{h r}\right) w_{3} \sum_{k} s_{k}+y_{h r} \sum_{k} w_{h k} s_{k} \equiv Y\left(y_{h}, s\right)$ subject to $y_{h r} \in\left[0, y_{h}\right]$ and $c_{h j}$ maximizes $\sum_{k} p_{h j k} u^{h}\left(c_{h j k}\right)$ subject to $\sum_{k} s_{k} c_{h j k} \leq Y\left(y_{h}, s\right)$.

Definition 2 An allocation is a total damage-contingent competitive allocation if it is feasible and if there exists $d=\left(d_{1}, d_{2}, \ldots, d_{K}\right)$ and $L=\left(L_{1}, L_{2}, \ldots, L_{K}\right)$ such that $y_{h r}$ maximizes $\left(y_{h}-y_{h r}\right) w_{3} \sum_{k} d_{k}+y_{h r} \sum_{k} w_{h k} d_{k} \equiv Y\left(y_{h}, d\right)$ subject to $y_{h r} \in\left[0, y_{h}\right], c_{h j}$ maximizes $\sum_{k} p_{h j k} u^{h}\left(c_{h j k}\right)$ subject to $\sum_{k} d_{k} c_{h j k} \leq$ $Y\left(y_{h}, d\right)$, and $L_{k}=N m_{k} \sum_{h} y_{h r}\left(R_{h} w_{2}-w_{1}\right)$.

In terms of a Walrasian auctioneer, the second equilibrium should be thought of as follows. The auctioneer calls out a list $\left(L_{k}, d_{k}\right)$ with $L_{k}<L_{k+1}$. People respond by maximizing as if $d_{k}$ were the price of a unit of output in aggregate state $k$. A proposal by the auctioneer and a response satisfies the definition if the responses are feasible and consistent with the announced contingent total damage quantities.

Having stated these definitions, the equivalence is obvious. That is, an allocation is an Arrow-Debreu competitive allocation if and only if it is a total damage-contingent competitive allocation. The argument simply identifies $s$ and $d$.

Several things follow from such equivalence. Allocations satisfying definition 2 exist and any such allocation is PE. In the special case of unanimity about the probabilities of the different aggregate states, we get additional conclusions about the equilibrium allocation, the prices, and the direction of trade that are analogous to those discussed in the last section. In particular, it then follows that each person's consumption is decreasing in total 
damage. That is, everyone participates in the aggregate risk, even those who invest only in the safe technology. They are persuaded to participate in the aggregate risk by being presented with odds that are favorable.

Finally, it is straightforward to use the equivalence to analyze the kind of catastrophe relief policy that we described earlier. In the endowment models, we saw that catastrophe relief is an income transfer from those with safe endowments to those with risky endowments. Now it is an income transfer from those with relatively poor risky technologies, the lower indexed types in our example, to those with better risky technologies, the higher indexed types. However, as is well known, catastrophe relief of that sort does more in this model; it acts like a subsidy on investment in the risky technology. That is, it tends to give rise to overinvestment in the risky technology and, thereby, gives rise to allocations that are not $\mathrm{PE}$.

\section{Concluding remarks}

Private markets have long provided arrangements for pooling risks related to natural forces when the chances for large aggregate losses were low. The most obvious arrangement is the familiar one of property insurance, financed either as a mutual enterprise of the insured or by equity investors. Insurance arrangements for transfering the risks of aggregate loss, though less prevalent, have also existed, for example, as sometimes brokered by Lloyds of London. Recently, new arrangements involving contingent securities that are more directly the analogs of those in our models have begun to emerge. In December 1992 the Chicago Board of Trade (CBOT) began trade in futures and options contracts whose payoff depends on measures of aggregate claims against insurance companies for losses due to natural catastrophes. These catastrophe futures and options have since been supplemented by futures and options contingent on the average yield achieved by corn producers in certain states in the US. In addition, some insurance companies have issued so-called "act of God" bonds, whose principal and/or coupon payments may depend on a measure of natural catastrophe losses ([1];[14];[19];[25];[35]).

Our models suggest that these private markets for transfering natural catastrophe risks will have certain properties that appear to have confused at least some observers. For example, some have suggested that markets for ctastrophe risk may be one-sided in the sense that they lack "natural sellers" of the insurance they provide $([4] ;[5] ;[17] ;[30] ;[33])$. Who, in other words, will 
be willing to bet against large aggregate losses? As noted above, our models suggest an answer: individuals who are not much directly exposed to those losses are the natural sellers of these contracts (provided they do not hold unusually pessimistic views on the likelihood of large losses). That is, the natural sellers do not have to be individuals who profit from catastrophes, as some accounts have suggested $([30])$. It is enough that they have little direct exposure to the catastrophes they insure.

Questions have also been raised about the likely rate of return on catastrophecontingent securities. Some have suggested that the price of a CBOT catastrophe futures contract should provide a consensus expectation of the losses that go into the contract's index $([4] ;[5])$. Others have viewed as a defect that the new contracts seem to offer unusually high expected returns to those providing aggregate loss insurance $([24])$. Implicit in both is the standard of actuarial fairness. However, our models suggest that the expected returns will indeed be high, relative to normal investment returns and to actuarially fair returns. Such discrepancies arise as an inherent part of optimal arrangements for sharing aggregate risks and do not imply that the markets for the new contracts are defective.

In the abstract economies we studied, government efforts to affect the sharing of natural disaster risks were potentially harmful and at best arbitrary or redundant. Thus, as has been noted before and often, government programs that provide natural disaster insurance at below-market prices will cause resources to shift towards the risky activities (see, for example, [28]). Nevertheless, several existing or proposed disaster relief programs seem very likely to have this effect. Outlays for the existng federal disaster programs - including the Federal Emergency Management Agency (FEMA), the National Flood Insurance Corporation, the Federal Crop Insurance Corporation - totaled about $\$ 34$ billion between 1989 and 1995 ([29]). These outlays were concentrated in hurricane-, earthquake-, and flood-prone regions but were funded by taxpayers nationwide. Because premiums in most federal insurance programs are explicitly subsidized and FEMA's assistance is delivered as aid, these federal programs provide net subsidies to residents and property owners in areas prone to natural disasters. Recent state efforts at disaster insurance may replicate some of the cross-subsidization distortions of the federal programs. Florida, for example, has created the Florida Hurricane Catastrophe Fund (FHCF) to provide reinsurance coverage to private insurers offering hurricane coverage ([16]). Although FHCF's exposure is concentrated in hurricane prone areas, its funding involves some general revenues 
and ultimately rests on its ability to assess surcharges on property insurance statewide $([6] ;[27])$. In addition, governments also provide or mandate subsidies to so-called mitigation efforts. These programs also subsidize a shift of resources into disaster-prone areas.

In our models, an important component of the overall risk-sharing mechanism is a freely functioning insurance market in the risk-prone areas that spreads the aggregate losses there evenly among all ex-ante identical parties. Actual markets for homeowners insurance markets are subject to regulation, including regulation of premiums, by state governments. Furthermore, insurance contracts have traditionally bundled insurance against individual risk with insurance against aggregate risk. The equilibrium price of this bundle of insurance services appears to have risen sharply in hurricane and earthquake prone areas in recent years, and regulators in some catastrophe-prone states may be limiting homeowners insurance premiums to unrealistically low levels. After Hurricane Andrew in 1992, for example, many Florida insurers revised upward their estimates of property risks in Florida and sought regulatory approval for higher premiums. Although the state's insurance commission approved substantial premium increases after 1992, many of the state's insurers still tried to reduce their Florida market share. The state government intervened to thwart this effort, passing laws that made it difficult for insurers to cancel or fail to renew coverage.

The restrictions that Florida imposed on policy cancelations did not prevent insurers from reducing property insurance coverage in the state. In fact, so many homeowners were unable to renew coverage at prevailing rates that the state began to provide homeowners insurance and reinsurance itself through the Florida Residential Property and Casualty Joint Underwriting Association (JUA). Because of its relatively attractive premiums, the JUA quickly became the second largest homeowners insurer in Florida, covering 18 percent of Florida's homes overall and an even higher share in hurricane-prone southern Florida ([26]). A similar pattern of rate regulation disputes followed by an "availability crisis" and new state catastrophe insurance programs has occurred in California and Hawaii. Some observers of these availability crises view them as evidence that private markets cannot provide optimal catastrophe risk sharing ([12]; [32];[33]). This alleged market failure may instead be an example of excessive government regulation, which has kept premiums below market-clearing levels. The fact that no comparable crisis developed in the relatively unregulated market for commercial property insurance bolsters this alternative view ([24]). 
Our models stress that optimal arrangements for sharing the risks of catastrophes include both within-region mutualization and cross-region bets on the extent of aggregate loss. As noted above, these separate components of optimal insurance have traditionally been bundled in private homeowners policies. The new state-run insurance programs in catastrophe-prone areas also promise policyholders both components. But individual state governments have no special advantages for providing cross-regional risk sharing. At best they can attempt to replicate private sector arrangements, by purchasing adequate reinsurance or using the new contingent claims markets. Worse outcomes are also possible, including vague and potentially infeasible proposals for floating and paying off bonds in the wake of a major catastrophe. If reliable arrangements are not made in advance, the actual outcomes may range from defaulting on obligations to policyholders to heavy reliance on within-state cross subsidies from less risky to more risky areas. Indeed, the emphasis on ex post borrowing in these schemes is misleading. What matters is who is liable to repay any such ex post borrowing. One likely alternative outcome is a set of taxes that on balance subsidizes the at-risk areas in a state by placing too much of the repayment burden on other areas in the state. This will not produce a flow of resources across multi-state regions and, as noted above, will contribute to resource misallocation.

We end with two qualifications concerning the rosy picture that we have painted of free-market solutions to allocating risks using total-damage contingent securities. First, governments at all levels may not be able to commit to not helping out those who experience losses arising from natrual catastrophes. Part of the solution seems simple: require that property owners be insured. Such a requirement is in place for those who have mortgages and it would seem a simple matter to extend it to everyone. Second, the kind of two-stage insurance scheme that we have used to describe optimal risk sharing is not, of course, the only possible scheme. It does, however, have one important virtue; it is transparent. In contrast, the bundling of the two stages that occurs under most current insurance policies is far from transparent. Holders of such bundled policies and owners and potential owners of insurance companies issuing such policies have an interest in knowing the aggregate risk exposure of the companies. But acquiring that information is very difficult. ${ }^{6}$ If insurance companies focused on providing mutual policies

\footnotetext{
${ }^{6}$ For an amusing instance of one insurance company's presumption that investors and policyholders did not understand its balance sheet, see the account by former Executive
} 
to those in comparable risk situations, they would be engaged in activities for which they have experience; namely, the setting of critieria for placing properties into comparable ex ante risk situations. They would be out of the business of assigning probabilities to different aggregate states, something they are not particularly well-suited to doing. It may, though, be quite reasonable for them to serve as intermediaries for their customers in the markets for bets on aggregate states.

Life official Gary Schulte, as discussed in [34]. 


\section{References}

[1] Borden, Sara, and Sarkar, Asani. 1996. Securitizing property catastrophe risk. Current Issues in Economics and Finance 2 (August): 6 pp. Federal Reserve Bank of New York.

[2] Cass, David; Chichilnisky, Graciela; and Wu, Ho-Mou. 1996. Individual risk and mutual insurance. Econometrica 64 (March): 333-341.

[3] Catalano, Peter. 1995. Hurricane alert! Popular Science 247 (September):65-70.

[4] Cox, Samuel H., and Schwebach, Robert G. 1992. Insurance futures and hedging insurance price risk. The Journal of Risk and Insurance 59 (December, no. 4): 628-44.

[5] D'Arcy, Stephen P., and France, Virginia Grace. 1992. Catastrophe futures: A better hedge for insurers. The Journal of Risk and Insurance 59 (December, No. 4): 575-601.

[6] Florida House of Representatives. 1995. House Bill 719, An act relating to the Florida Hurricane Catastrophe Fund.

[7] Gray, William M. 1990. Strong association between West African rainfall and U.S. landfall of intense hurricanes. Science 249 (September 14th, n4974): 1251-6.

[8] Gutscher, Cecile. 1997. "Catastrophe Bonds Are Latest Investment Tools That Bet on Risks of Weather, Natural Disasters." Wall Street Journal, November 7, p. C22 (Midwestern Edition).

[9] Hofmann, Mark A. 1996. Insurers fall short if Big One hits: ISO. Business Insurance (May 20): 2, 40.

[10] King, Rawle O. 1994. U.S. natural disasters: State exposures and private insurance coverage. CRS Report for Congress 94-991 E. Washington, D.C.: Congressional Research Service, The Library of Congress.

[11] Kunreuther, Howard. 1995. "Mitigating Disaster Losses Through Insurance." Wharton Risk Management and Decision Processes Center, Working Paper 95-09-02. 
[12] Lewis, Christopher M., and Murdock, Kevin C. 1996. The role of government contracts in discretionary reinsurance markets for natural disasters. Typescript, Christopher M. Lewis, Office of Federal Housing Enterprise Oversight, February.

[13] Marshall, John M. 1974. Insurance theory: Reserves versus mutuality. Economic Inquiry 12 (December): 476-92.

[14] McGee, Suzanne, and Scism, Leslie. 1996. Disaster bonds have investors "rolling the dice with God." The Wall Street Journal (August 19): C1.

[15] Miranda, Mario J. and Joseph W. Glauber. 1997. "Systemic Risk, Reinsurance, and the Failure of Crop Insurance Markets." American Journal of Agricultural Economics, v.79, pp. 206-215 (February).

[16] Navarro, Mireya. 1996. Florida facing crisis in insurance. The New York Times (April 25): A8.

[17] Niehaus, Greg, and Mann, Steven V. 1992. The trading of underwriting risk: An analysis of insurance futures contracts and reinsurance. The Journal of Risk and Insurance 59 (December, no. 4): 601-27.

[18] Nishenko. S.P. 1989. "Circum-Pacific Seismic Potential: 1989-1999." U.S. Dept. of Interior Geological Survey, National Earthquake Information Center, U.S. Geological Survey Open File Report 89-86. Risk. 1997.(December, p. 52).

[19] Quint, Michael. 1995. New tools spread risks of insurers. The New York Times (May 15): A1, C2.

[20] Risk. 1997. (December, p. 52)

[21] Risk Management Solutions (RMS), Inc. 1995a. What if the 1906 earthquake strikes again?: A San Francisco Bay area scenario. Topical Issues Series (May). Menlo Park, Calif.: RMS, Inc. 81 pp.

[22] _ _ _ 1995b. What if a major earthquake strikes the Los Angeles area? Topical Issues Series (September). Menlo Park, Calif.: RMS, Inc. 85 pp. 
[23] _ _ _ 1995c. What if the 1923 earthquake strikes again?: A five-prefecture Tokyo region scenario. Topical Issues Series (November). Menlo Park, Calif.: RMS, Inc. 97 pp.

[24] Schachner, Michael. 1996. The fundamental problem: Insurer executives bemoan low rates for high risks. Business Insurance (January 22).

[25] Scism, Leslie. 1997. "Investors in USAA 'Disaster Bonds' Could Get the Wind Knocked Out of Them if Storms Strike." Wall Street Journal, June 18, p. C19 (Midwestern Edition).

[26] Scism, Leslie, and Brannigan, Martha. 1996. Through the roof: Florida homeowners find insurance pricey, if they find it at all. The Wall Street Journal (July 12): 1

[27] Stieghorst, Tom. 1996. "Florida Leads Field in Catastrophe Funds." Fort Lauderdale Sun-Sentinel, July 10, p. 1A.

[28] Stossel, John. 1995. Swept away by welfare for the wealthy. Wall Street Journal (August 16): A10.

[29] Summers, Lawrence H. 1996. Prepared testimony before the Senate Committee on Commerce, Science and Transportation, Thursday, July 18, 1996. 00179447 subfile: FNS. Fed Log A1-A2. Washington, D.C.: Federal News Service.

[30] The Economist. 1994. On shaky ground. The Economist (December 3).

[31] The Economist, 1997. "Nature rarely repeats itself." August 2, pp. 6364 .

[32] Thompson, Mozelle W. 1995a. Prepared statement before the House Transportation and Infrastructure Committee, Subcommittee on Water Resources and Environment, Tuesday, December 5, 1995. 00168481 Subfile: FNS. Washington, D.C.: Federal News Service. . 1995b. Administration policy paper natural disaster insurance and related issues. Paper presented to the House Transportation and Infrastructure Committee, Subcommittee on Water Resources and Environment, Tuesday, December 5, 1995. 00168481 Subfile: FNS. Washington, D.C.: Federal News Service. 
[34] Todd, Richard M. and Neil Wallace. 1992. "SPDAs and GICs: Like money in the bank." Federal Reserve Bank of Minneapolis Quarterly Review, Vol. 16, No. 3, Summer 1992, pp. 2-17.

[35] Treaster, Joseph B. 1997. "Even Nature Can Be Turned Into a Security." New York Times, August 6, pp. C1, C6.

[36] Wesnousky. S.G., C.H. Sholz, K. Shimazaki, and T. Matsuda. 1984. "Integration of Geological and Seismological Data for the Analysis of Seismic Hazard: A Case Study of Japan." Bulletin of the Seismological Society of America, v. 74, n. 2, pp. 687-708 (April). 